\title{
Geographic impact on access to care and survival for non-curative esophagogastric cancer: a population-based study
}

\author{
Elliott K. Yee ${ }^{1,2} \cdot$ Natalie G. Coburn 2,3,4,5 Victoria Zuk $^{2}$ - Laura E. Davis ${ }^{6}$. Alyson L. Mahar ${ }^{7}$. Ying Liu ${ }^{4}$. \\ Vaibhav Gupta $^{2,4} \cdot$ Gail Darling ${ }^{4,8,9} \cdot$ Julie Hallet ${ }^{2,3,4,5}$
}

Received: 11 October 2020 / Accepted: 6 January 2021 / Published online: 6 February 2021

(c) The International Gastric Cancer Association and The Japanese Gastric Cancer Association 2021

\begin{abstract}
Background Among patients not undergoing curative-intent therapy for esophagogastric cancer, access to care may vary. We examined the geographic distribution of care delivery and survival and their relationship with distance to cancer centres for non-curative esophagogastric cancer, hypothesising that patients living further from cancer centres have worse outcomes. Methods We conducted a population-based analysis of adults with non-curative esophagogastric cancer from 2005 to 2017 using linked administrative healthcare datasets in Ontario, Canada. Outcomes were medical oncology consultation, receipt of chemotherapy, and overall survival. Using geographic information system analysis, we mapped locations of cancer centres and outcomes across census divisions. Bivariate choropleth maps identified regional outcome discordances. Multivariable regression models assessed the relationship between distance from patient residence to the nearest cancer centre and outcomes, adjusting for demographic, clinical, and socioeconomic factors.

Results Of 10,228 patients surviving a median 5.1 months (IQR: 2.0-12.0), 68.5\% had medical oncology consultation and $32.2 \%$ received chemotherapy. Certain distances (reference $\leq 10 \mathrm{~km}$ ) were associated with lower consultation [relative risk 0.79 (95\% CI $0.63-0.97$ ) for $\geq 101 \mathrm{~km}$ ], chemotherapy receipt [relative risk 0.67 (95\% CI 0.53-0.85) for $\geq 101 \mathrm{~km}$ ], and overall survival [hazard ratio 1.07 (95\% CI 1.02-1.13) for 11-50 km, hazard ratio 1.13 (95\% CI 1.04-1.23) for 51-100 km]. Conclusion A third of patients did not see medical oncology and most did not receive chemotherapy. Outcomes exhibited high geographic variability. Location of residence influenced outcomes, with inferior outcomes at certain distances $>10 \mathrm{~km}$ from cancer centres. These findings are important for designing interventions to reduce access disparities for non-curative esophagogastric cancer care.
\end{abstract}

Keywords Esophagus $\cdot$ Stomach $\cdot$ Cancer $\cdot$ Outcomes $\cdot$ Geography

Part of this work was presented as a podium presentation at the American Society of Clinical Oncology Gastrointestinal Cancers Symposium in January 2020 in San Francisco, CA, and as a virtual poster presentation at the Society of Surgical Oncology International Conference on Surgical Cancer Care in August 2020.

Julie Hallet

Julie.hallet@sunnybrook.ca

1 Faculty of Medicine, University of Toronto, Toronto, ON, Canada

2 Cancer Program, Evaluative Clinical Sciences, Sunnybrook Research Institute, 2075 Bayview Avenue, Toronto, ON M4N 3M5, Canada

3 Department of Surgery, Odette Cancer Centre, Sunnybrook Health Sciences Centre, Toronto, ON, Canada

4 Department of Surgery, University of Toronto, Toronto, ON, Canada
5 ICES, Toronto, ON, Canada

6 Department of Epidemiology, Biostatistics and Occupational Health, McGill University, Montreal, QC, Canada

7 Department of Community Health Sciences, University of Manitoba, Winnipeg, MB, Canada

8 Cancer Clinical Research Unit, Princess Margaret Cancer Centre, Toronto, ON, Canada

9 Toronto General Hospital Research Institute, Toronto General Hospital, Toronto, ON, Canada 


\section{Introduction}

Esophagogastric cancers rank among the highest cancers for years of life lost globally [1]. Though cure at early stages is possible via resection or chemoradiation, patients often present with late-stage disease and most are unable to undergo curative-intent treatment [2-4]. Nevertheless, non-curative systemic therapy can improve survival while reducing symptom burden and slowing disease progression [5-10].

It is unknown whether patients are able to consistently access systemic therapy for non-curative esophagogastric cancer should they choose to do so. Geography may play an important role in access to cancer care [11]. Much of the existing literature concerning geography in cancer has focused on surgically treatable cancers [12-17]. Prior work has shown that investigations, treatment, and survival vary with geography for metastatic gastric cancer [18, 19]. Community material deprivation was found to be associated with lower rates of oncology assessment and cancerdirected therapy among patients with non-curative gastrointestinal cancers [20]. For patients with non-curative pancreatic cancer, place of residence in relation to cancer facilities was specifically shown to impact access to care and survival [21]. This potential relationship is important to understand to better care delivery and outcomes but has yet to be explored for non-curative esophagogastric cancer.

To characterise how gaps in care for non-curative esophagogastric cancer may be related to geography, we performed a population-based study investigating the association between distance from cancer facilities and rates of medical oncology consultation, receipt of cancer-directed therapy, and survival. We also sought to describe regional trends in these outcomes. We hypothesised that outcomes vary with geography, and that patients living further from cancer facilities have worse outcomes.

\section{Methods}

\section{Study design and setting}

We performed a population-based retrospective cohort study using data from linked administrative datasets from ICES (formerly known as the Institute for Clinical Evaluative Sciences) in Ontario, Canada. As of 2016, the province of Ontario had a population of 13,448,494 and a land area of $908,669 \mathrm{~km}^{2}$. Ontario's population receives publicly funded universal healthcare through the Ontario Health Insurance Plan (OHIP) as per the Canada Health Act [22]. This study was approved by the Research Ethics Board of Sunnybrook Health Sciences Centre. Results were reported according to the REporting of studies Conducted using Observational Routinely collected health Data (RECORD) statement [23]. The design of this study was adapted from that of a previous study of pancreatic cancer [21].

\section{Study population and cohort}

The study population comprised all patients in Ontario with a valid OHIP number diagnosed with esophagogastric cancer, defined as esophageal or gastric adenocarcinoma or squamous cell carcinoma, who did not receive curativeintent treatment, defined as esophagectomy, gastrectomy, or non-palliative chemoradiation therapy (eTable 1 in the Supplement) [4, 24-28]. Patients with diagnoses from January 1, 2005 to December 31, 2017 were included.

\section{Data sources}

Information about data sources is summarised in eTable 2 in the Supplement. Using each patient's unique Identification Key Number, we linked administrative healthcare datasets from ICES. Demographic and vital status data are contained in the Registered Persons Database (RPDB) [29]. Information about all patients in Ontario diagnosed with cancer, excluding non-melanoma skin cancer, is contained in the Ontario Cancer Registry (OCR) [30]. Information about health services provided to patients is contained in the National Ambulatory Care Reporting System (NACRS) and the Canadian Institute for Health Information Discharge Abstract Database (CIHI-DAD) and Same Day Surgery (CIHI-SDS) Database [31]. The OHIP Claims Database contains information about provider billing for healthcare services. The Cancer Activity Level Reporting (ALR) database contains information about in-hospital chemotherapy, supportive medication, and radiotherapy.

The Postal Code Conversion File (PCCF) links postal codes to census geographic regions in Canada [32]. One such region is the census division, of which there are 49 in Ontario (eFigure 1 in the Supplement) [33]. Geospatial data pertaining to Ontario's census divisions as of the 2016 census were obtained from Statistics Canada [34]. Centres providing systemic cancer therapy were identified from a list maintained by Cancer Care Ontario [35]. These cancer centres are classified hierarchically into 4 levels based on complexity of care and services provided. Level 1 and Level 2 centres are regional cancer centres, with Level 1 centres maintaining teaching and research responsibilities. Level 3 centres are affiliate sites, and Level 4 centres are satellite sites with no onsite medical oncologists. The point location of each cancer centre with 
onsite medical oncology (Levels 1-3) was determined with latitude and longitude using Google Maps 3.35 (Google, Mountainview, CA, USA).

\section{Exposure}

The exposure of interest was the straight-line distance from the centroid of each patient's postal code of residence to the nearest Level 1, 2 or 3 cancer centre, which served as a patient-level measure of access to care [36]. Straight-line distance has been used extensively in studies of geographic access to care $[14,15,21,37-42]$. Distance was categorised as $\leq 10 \mathrm{~km}, 11-50 \mathrm{~km}, 51-100 \mathrm{~km}$, and $\geq 101 \mathrm{~km}$ based on the distribution of distances across the study population, which demonstrated clustering consistent with residence in communities of varying urbanicity and remoteness. For this reason, as well as to facilitate the clinical applicability of results, the distance variable was categorical rather than linear.

\section{Outcomes}

The outcomes of interest were medical oncology consultation, receipt of chemotherapy, and overall survival as previously described $[4,21,43]$. Definitions are detailed in eTable 1 in the Supplement. Medical oncologists were defined as physicians submitting OHIP billing codes for chemotherapy during the study period. Consultations were defined by consultation billing codes from medical oncologists from date of diagnosis to end of follow-up. Receipt of chemotherapy was defined by billing codes for two or more cycles of chemotherapy from date of diagnosis to end of follow-up. Overall survival was defined from date of diagnosis until date of death in the RPDB. The end of follow-up was defined as the earliest of date of death or date of end of study, defined as March 31, 2018, providing the opportunity for a minimum of 3 months of follow-up for all included patients.

\section{Covariates}

Covariate definitions and data sources are described in eTable 1 in the Supplement. Age and sex were abstracted from the RPDB. Year of diagnosis was abstracted from the OCR. Material Deprivation Quintile, a subset of the Ontario Marginalization Index (ON-Marg), is an ecologic measure of material socioeconomic status and was assigned to each patient according to postal code [44]. The Elixhauser comorbidity index was used to assign each patient's comorbidity burden, and high comorbidity burden was defined as Elixhauser index $\geq 4[25,26]$.

\section{Statistical analysis}

Descriptive analyses described baseline cohort characteristics stratified by category of distance from place of residence to the nearest cancer centre. Continuous variables were reported as median with interquartile range (IQR) and categorical variables as absolute number (n) with proportion (\%). Comparison testing was performed by the Kruskal-Wallis and Chi-square tests for continuous and categorical variables, respectively. Risks of medical oncology consultation and receipt of chemotherapy were estimated by Modified Poisson regression with robust error variance and reported as relative risk (RR) with $95 \%$ confidence interval (95\% CI). Risk of death was estimated by Cox Proportional Hazards regression and was reported as hazard ratio (HR) with $95 \%$ CI. RR and HR were reported using the $\leq 10 \mathrm{~km}$ distance category as the reference.

Adjusted multivariable regression models assessed the relationship between distance and the outcomes of interest. Models were adjusted for the following covariates, which were identified a priori as potential confounders based on existing literature and clinical relevance: age (categorical), sex, year of diagnosis (2005-2011 vs. 2012-2017), comorbidity burden (dichotomous), and Material Deprivation Quintile [21, 45-48]. Data for Material Deprivation Quintile were missing in $0.9 \%$ of the cohort. A complete case analysis approach was used such that cases with missing data were excluded.

Patients were linked to their census divisions of residence using the PCCF. Univariate choropleth maps of the primary outcomes across census divisions were created to visualise geographic trends in outcomes in relation to the locations of cancer centres [37]. Bivariate choropleth maps of pairs of primary outcomes were then created. Whereas a univariate choropleth map displays only one variable, a bivariate approach allows for the visualisation of two variables in a single map by representing each with a distinct colour gradient, whereby the tonally additive result of the overlapping gradients can describe each areal unit's degree of concordance or discordance between the variables [49-51]. All maps were created with the geographic information system (GIS) software QGIS 2.12 (QGIS Geographic Information System, Open Source Geospatial Foundation Project).

A subgroup analysis was performed to assess the relationship between distance to the nearest cancer centre and receipt of chemotherapy among patients who received medical oncology consultation and thereby had realised entry into the cancer care system. To distinguish potential differences in care delivery and outcomes between esophageal and gastric cancer, a sensitivity analysis was then performed in which the relationship between distance and each of the primary outcomes was assessed separately for each cancer. 
Table 1 Characteristics of included patients, stratified by distance from place of residence to nearest cancer centre

\begin{tabular}{|c|c|c|c|c|c|c|}
\hline Characteristics & $\leq 10 \mathrm{~km} n=6381$ & $11-50 \mathrm{~km} n=2764$ & $51-100 \mathrm{~km} n=651$ & $\geq 101 \mathrm{~km} n=432$ & All patients $n=10,228$ & $p$ value \\
\hline \multicolumn{7}{|l|}{ Age (years old) } \\
\hline$\leq 60$ & $1447(22.7 \%)$ & $685(24.8 \%)$ & $162(24.9 \%)$ & $118(27.3 \%)$ & $2412(23.6 \%)$ & \multirow[t]{4}{*}{$<.001$} \\
\hline $61-70$ & $1405(22.0 \%)$ & $706(25.5 \%)$ & $173(26.6 \%)$ & $107(24.8 \%)$ & $2391(23.4 \%)$ & \\
\hline $71-80$ & $1674(26.2 \%)$ & $744(26.9 \%)$ & $171(26.3 \%)$ & $131(30.3 \%)$ & $2720(26.6 \%)$ & \\
\hline$\geq 81$ & $1855(29.1 \%)$ & $629(22.8 \%)$ & $145(22.3 \%)$ & $76(17.6 \%)$ & $2705(26.4 \%)$ & \\
\hline Female sex & $2286(35.8 \%)$ & $816(29.5 \%)$ & $153(23.5 \%)$ & $113(26.2 \%)$ & $3368(32.9 \%)$ & $<.001$ \\
\hline \multicolumn{7}{|l|}{ Year of diagnosis } \\
\hline 2005-2011 & $3269(51.2 \%)$ & $1,318(47.7 \%)$ & $320(49.2 \%)$ & $211(48.8 \%)$ & $5118(50.0 \%)$ & \multirow[t]{2}{*}{0.017} \\
\hline 2012-2017 & $3112(48.8 \%)$ & $1,446(52.3 \%)$ & $331(50.8 \%)$ & $221(51.2 \%)$ & $5110(50.0 \%)$ & \\
\hline $\begin{array}{l}\text { High comorbidity burden } \\
\text { (Elixhauser index } \geq 4 \text { ) }\end{array}$ & $796(12.5 \%)$ & $347(12.6 \%)$ & $90(13.8 \%)$ & $52(12.0 \%)$ & $1285(12.6 \%)$ & 0.778 \\
\hline \multicolumn{7}{|l|}{ Material deprivation quintile } \\
\hline Missing & $33(0.5 \%)$ & $24(0.9 \%)$ & $11(1.7 \%)$ & $24(5.6 \%)$ & $92(0.9 \%)$ & \multirow[t]{6}{*}{$<.001$} \\
\hline 1st-least deprived & $905(14.2 \%)$ & $596(21.6 \%)$ & $58(8.9 \%)$ & $32(7.4 \%)$ & $1591(15.6 \%)$ & \\
\hline 2nd & $1069(16.8 \%)$ & $647(23.4 \%)$ & $113(17.4 \%)$ & $67(15.5 \%)$ & $1896(18.5 \%)$ & \\
\hline $3 r d$ & $1116(17.5 \%)$ & $642(23.2 \%)$ & $166(25.5 \%)$ & $106(24.5 \%)$ & $2030(19.8 \%)$ & \\
\hline 4 th & $1412(22.1 \%)$ & $533(19.3 \%)$ & $156(24.0 \%)$ & $119(27.5 \%)$ & $2220(21.7 \%)$ & \\
\hline 5th-most deprived & $1846(28.9 \%)$ & $322(11.6 \%)$ & $147(22.6 \%)$ & $84(19.4 \%)$ & $2399(23.5 \%)$ & \\
\hline
\end{tabular}

Statistical significance was defined as $p \leq 0.05$ and all analyses were two sided. All statistical analysis was performed with SAS Enterprise Guide 6.1 (SAS Institute, Cary, NC, USA).

\section{Results}

\section{Description of cohort}

10,228 patients were included in the study cohort (eFigure 2 in the Supplement). 3623 (35.4\%) had esophageal cancer and 6605 (64.6\%) had gastric cancer. Demographic and clinical characteristics of the cohort stratified by distance are presented in Table 1 . The oldest patients were less likely to live further from cancer centres.

\section{Outcomes}

$7011(68.5 \%)$ patients consulted medical oncology and 3297 (32.2\%) patients received chemotherapy. The most common first-line regimens used were cisplatinum monotherapy in $45.6 \%(n=1,503), 5$-FU monotherapy in $29.0 \%(n=957)$, and cisplatinum combination therapy in $19.5 \%(n=643)$. Median survival for the entire cohort was 5.1 months (IQR 2.0-12.0). Median survival was 5.2 months (IQR 2.1-11.0) for patients with esophageal cancer and 5.1 months (IQR 1.9-12.8) for patients with gastric cancer.

\section{Geographic mapping analysis}

Univariate choropleth maps exhibit regional variation in medical oncology consultation, receipt of chemotherapy, and survival (eFigures 3-5 in the Supplement). Across census divisions, medical oncology consultation ranged from 45 to $81 \%$, receipt of chemotherapy from 0 to $47 \%$, and median survival from 1.2 to 14.9 months. Cancer centres clustered heavily in the southern part of Ontario and were most concentrated in and around Toronto, the province's largest metropolitan region.

Bivariate choropleth maps exhibit regions of concordance and discordance between outcomes. Census divisions with concordantly high medical oncology consultation and receipt of chemotherapy clustered in the southern metropolitan regions of Ontario, whereas concordantly low oncology consultation and receipt of chemotherapy predominated in northern regions (Fig. 1). Census divisions with high survival, respectively, overlapping high oncology consultation and high receipt of chemotherapy were associated with metropolitan regions, with some distribution in more northern regions (Figs. 2 and 3). Pairs of outcomes had distinct patterns of discordance. The northernmost part of the province exhibited adjacent census divisions with high survival despite low oncology consultation (Fig. 2). Scattered census divisions demonstrated low receipt of chemotherapy despite high oncology consultation and high receipt of chemotherapy despite low oncology consultation (Fig. 1), low survival despite high oncology consultation (Fig. 2), and low survival 


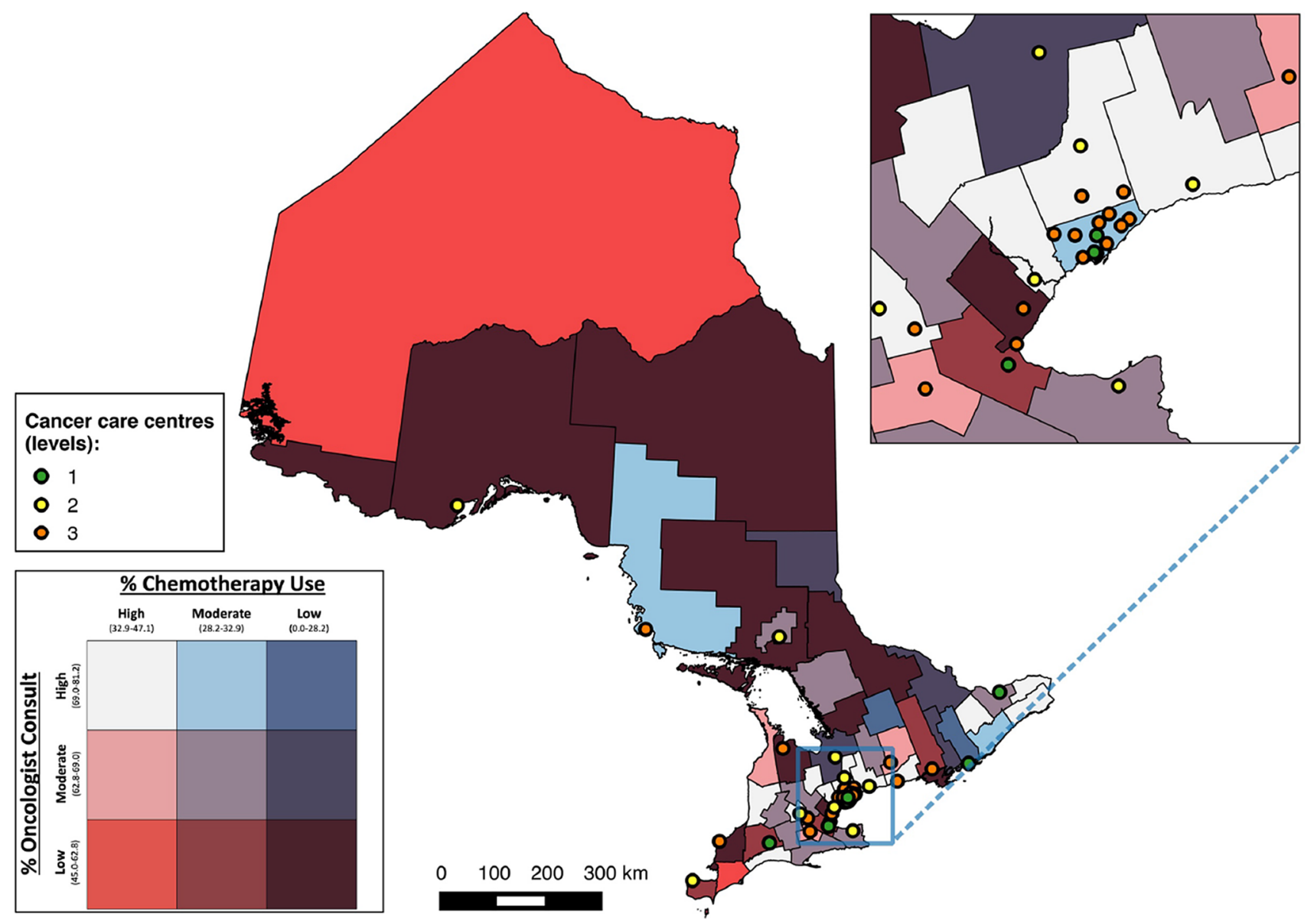

Fig. 1 Bivariate choropleth map of the distribution of medical oncology consultation and receipt of chemotherapy by Census Division in Ontario, Canada. Low, moderate, and high values, respectively, denote the 1st, 2nd, and 3rd terciles for each variable

despite high receipt of chemotherapy and high survival despite low receipt of chemotherapy (Fig. 3).

\section{Association between distance to nearest cancer centre and outcomes}

Adjusted effect estimates of the association between distance from place of residence to the nearest cancer centre and each of oncology consultation, receipt of chemotherapy, and overall survival are presented in Table 2. Compared to patients living $\leq 10 \mathrm{~km}$ from the nearest centre, residence $\geq 101 \mathrm{~km}$ was significantly associated with lower oncology consultation [RR 0.79 (95\% CI 0.63-0.97)] and lower receipt of chemotherapy [RR 0.67 (95\% CI 0.53-0.85)]. Residence $11-50 \mathrm{~km}$ and $51-100 \mathrm{~km}$ from the nearest centre was significantly associated with worse overall survival [HR 1.07 (95\% CI 1.02-1.13) and HR 1.13 (95\% CI 1.04-1.23), respectively]. Residence $\geq 101 \mathrm{~km}$ was not significantly associated with worse overall survival.

In a subgroup analysis of the 7011 patients who consulted medical oncology, distance $\geq 101 \mathrm{~km}$ remained significantly associated with lower receipt of chemotherapy [RR 0.85 (95\% CI 0.74-0.97)], albeit with a reduced magnitude (RR 0.85 vs. RR 0.67$)$.

In a sensitivity analysis of distance-outcome relationships for each of esophageal and gastric cancer, trends for each cancer were consistent with those of the combined cohort, albeit with fewer significant associations in the context of fewer patients within each distance category. Results of this sensitivity analysis are summarised in eTable 3 in the Supplement.

\section{Discussion}

In this geography-based study, we evaluated the impact of physical location on care delivery and survival for noncurative esophagogastric cancer. Using choropleth maps, we identified high interregional variability in rates of oncology consultation, receipt of chemotherapy, and overall survival, and also identified regional discordances between pairs of outcomes. We additionally demonstrated that patients living 


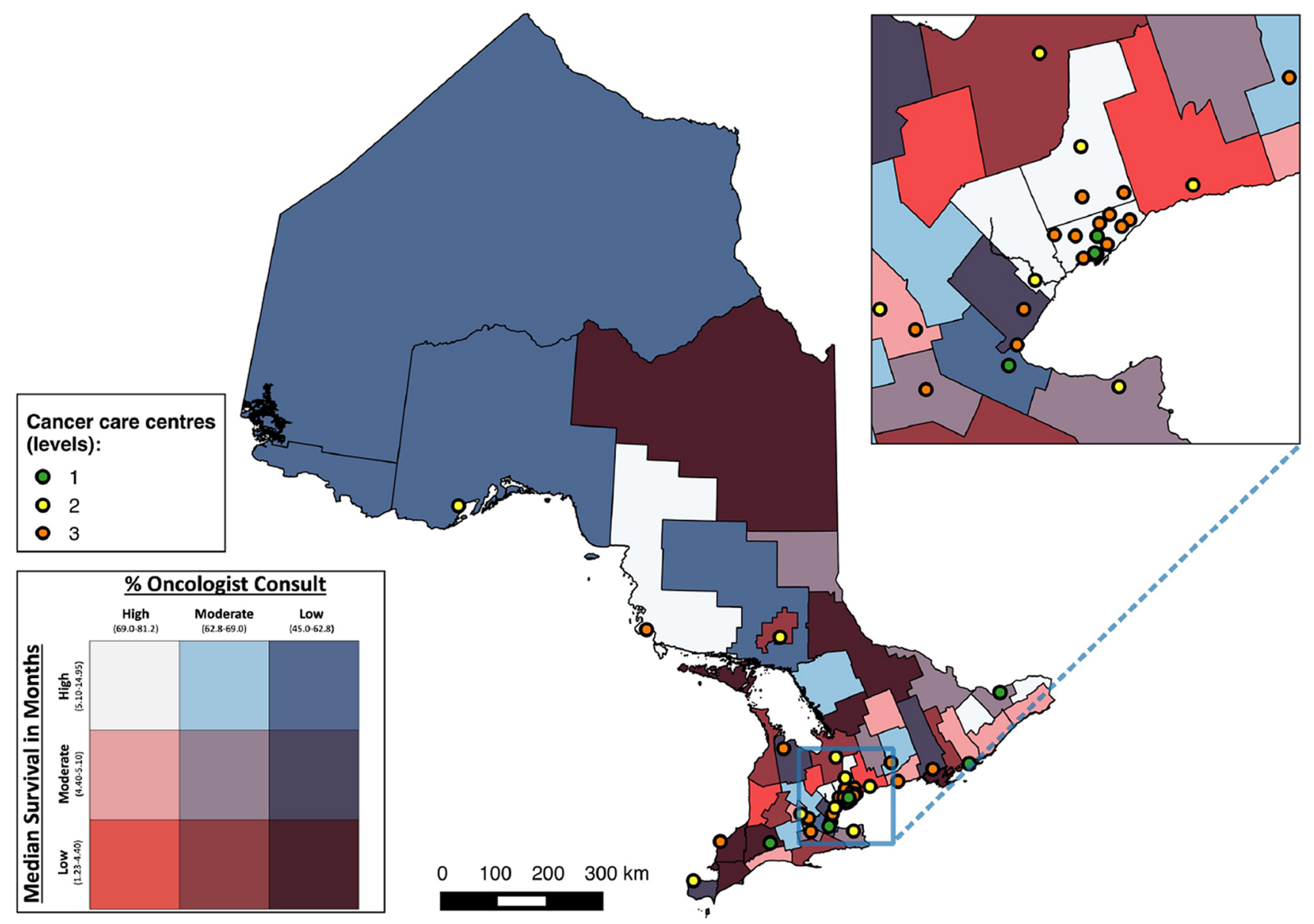

Fig. 2 Bivariate choropleth map of the distribution of medical oncology consultation and median survival by Census Division in Ontario, Canada. Low, moderate, and high values, respectively, denote the 1 st, 2 nd, and 3rd terciles for each variable

the furthest from cancer centres have lower rates of oncology consultation and receipt of chemotherapy, and that patients living at moderate distances have worse overall survival.

The present study contributes to an emerging body of geography-based research on non-curative cancers and to our knowledge is the first application of such methods for non-curative esophagogastric cancer [18, 19, 21, 52]. This approach has unique strengths. Combining distance analysis with choropleth mapping reveals patterns of care access at the patient and regional levels, thereby informing both clinical and administrative decision-making to reduce disparities in care and outcomes [21]. A non-curative cancer population is ideal for examining the impact of distance on care delivery in that systemic therapy can be delivered at a single location. Additionally, the setting of this study within a universal healthcare system ensured that insurance status did not confound access to care, thereby providing an ideal context to examine "physical accessibility" as defined by the World Health Organization [53]. Our findings are nevertheless generalisable to other healthcare systems owing to Ontario's diverse geography of both metropolitan and remote communities, which was captured by the distance categories used in our analysis. For instance, the distribution of oncology services across rural and urban regions in the United States similarly exhibits high geographic variability [54].

The negative impact of distance on outcomes is consistent with prior research in cancer care $[12,13,16,17,21$, 38, 55-57]. Specific trends within this distance-outcome relationship carry important implications for clinicians and policymakers. The reduced impact of distance on receipt of therapy among patients who first received oncology consultation suggests that much of the distance burden lies in entering the cancer care system via oncologist assessment. Similar findings have previously been reported, including by our group for pancreatic cancer [21, 38, 52]. In the present study, this could be due to patients accessing chemotherapy at nearby satellite centres so long as they have first consulted a medical oncologist $[21,35]$. That survival was worst at moderate distance $(11-100 \mathrm{~km})$ is also consistent with our group's findings for pancreatic cancer. Although our analysis may have been underpowered to detect a distance-survival 


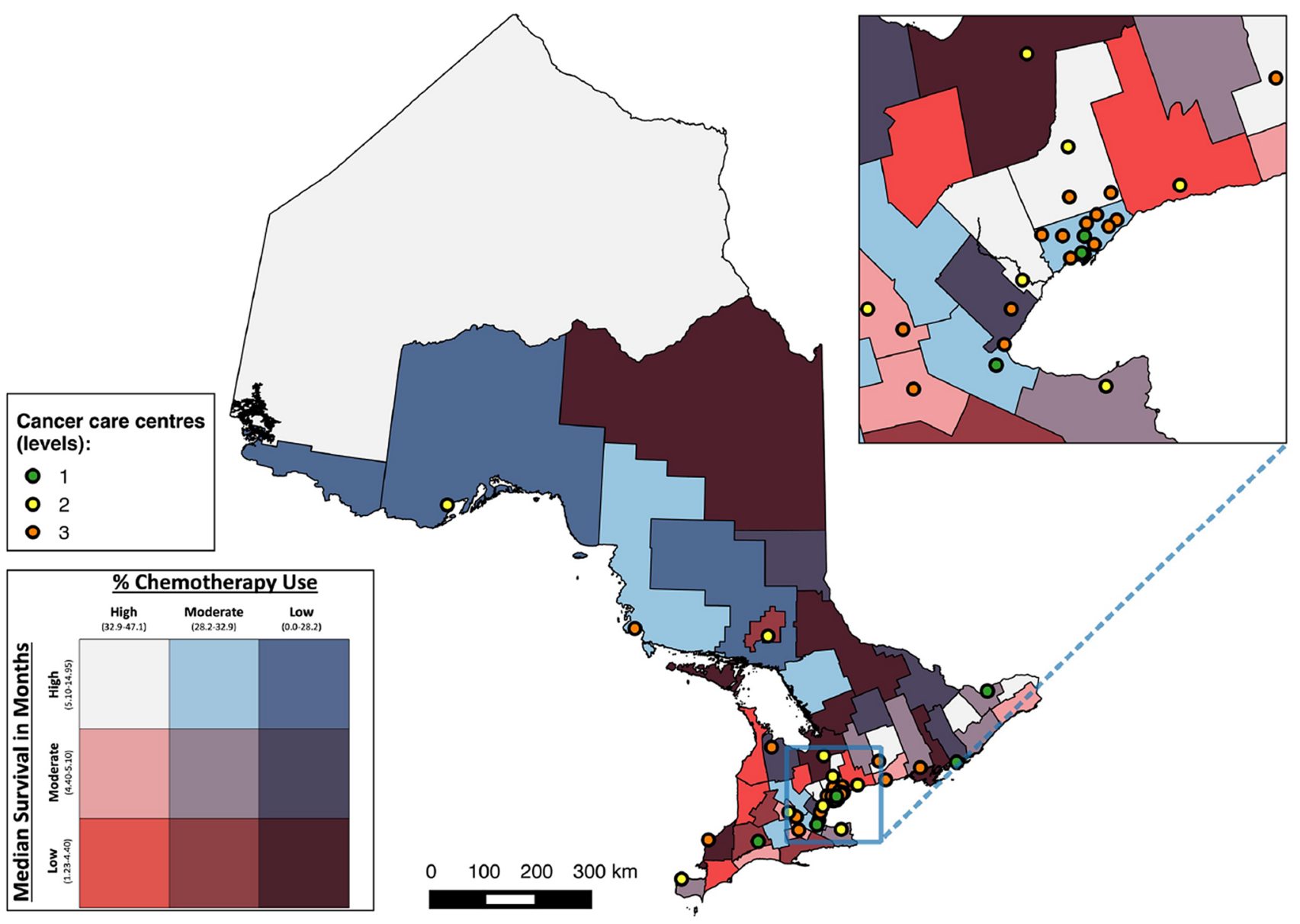

Fig. 3 Bivariate choropleth map of the distribution of receipt of chemotherapy and median survival by Census Division in Ontario, Canada. Low, moderate, and high values, respectively, denote the 1st, 2nd, and 3rd terciles for each variable

Table 2 Adjusted risk estimates for the association between distance from residence to the nearest cancer centre and outcomes

\begin{tabular}{|c|c|c|c|c|c|c|}
\hline \multirow[t]{2}{*}{$\begin{array}{l}\text { Distance to nearest } \\
\text { cancer centre }(\mathrm{km})\end{array}$} & \multicolumn{2}{|c|}{$\begin{array}{l}\text { Medical oncology consul- } \\
\text { tation }\end{array}$} & \multicolumn{2}{|c|}{ Receipt of chemotherapy } & \multicolumn{2}{|c|}{ Overall survival } \\
\hline & Relative risk* & $95 \%$ CI & Relative risk* & $95 \%$ CI & Hazard ratio* & $95 \%$ CI \\
\hline \multicolumn{7}{|l|}{$\leq 10(\operatorname{Ref})$} \\
\hline $11-50$ & 0.97 & $0.90-1.05$ & 0.97 & $0.87-1.08$ & 1.07 & $1.02-1.13$ \\
\hline $51-100$ & 0.95 & $0.81-1.12$ & 0.99 & $0.76-1.29$ & 1.13 & $1.04-1.23$ \\
\hline$\geq 101$ & 0.79 & $0.63-0.97$ & 0.67 & $0.53-0.85$ & 1.09 & $0.98-1.21$ \\
\hline
\end{tabular}

*Adjusted for age, sex, year of diagnosis, comorbidity burden, and material deprivation quintile relationship at $\geq 101 \mathrm{~km}$ given the small size of this category $(n=432)$, this trend could also reflect beneficial social and behavioural factors among the most remote patients as previously described, such as stronger social networks and greater propensity to travel further for more effective treatment [21, $58,59]$. In designing accessible cancer care systems, policymakers should remain cognizant that access to care and survival are sensitive to proximity to cancer centres, and that such opportunities for even modest improvements in survival could hold great importance for patients with non-curative esophagogastric cancer given its poor prognosis $[1,4]$.
The regional outcome discordances revealed by our mapping analysis suggest unique opportunities for focused investigations. Regions with poor outcomes despite favourable access to consultation and treatment may benefit from evaluation of unaddressed system-level inefficiencies in care delivery, whereas regions with favourable outcomes despite poor access could provide insight into protective community-level programmes not yet adopted by other regions [21]. Such programmes have been described in the United States and could serve to facilitate regional access to the cancer care system through community outreach, 
cancer education, and involvement in clinical trials [54]. Outcome disparities seen across the entire jurisdiction under study nevertheless necessitate widespread intervention to improve access to care and survival for noncurative esophagogastric cancer.

We propose three areas that interventions should target. First, equitable access to care should be established across regions. This would require facilitating entry into the cancer care system via medical oncology consultation for the most geographically disadvantaged patients. Established telemedicine infrastructure offers a potential solution [54, 60, 61]. How telemedicine services may be optimised to best serve remote patients with non-curative esophagogastric cancer is therefore an important area for future research. Second, geographic variation in outcomes should be addressed. Provision of care by high-volume providers has long been associated with superior outcomes for cancer surgery [62-64]. More recently, care by high-volume medical oncologists has been associated with superior receipt of chemotherapy and overall survival $[4,65]$. In non-curative esophagogastric cancer, high-volume medical oncologists have also been associated with lower healthcare costs [66]. Ensuring widespread geographic access to high-volume medical oncology services is, therefore, an economically viable approach to improving outcomes for this disease. Third, access to highvolume medical oncology care should be established in a way that minimises distance to cancer centres, given the potential for high-volume care to be less geographically accessible [42, 67, 68]. Recent work using GIS analysis has demonstrated that existing cancer centres can be reorganised to provide high-volume care without increasing travel distance for patients undergoing pancreaticoduodenectomy [69]. Applied to non-curative esophagogastric cancer, such an approach could improve care delivery and survival without exacerbating geographic barriers.

This study has some limitations. The datasets we used were not designed specifically for this study, and thus, certain patient characteristics, such as cancer stage, could not be accounted for. Similarly, we were unable to capture care delivery that may have occurred outside of Ontario, though this would be unusual. Although we cannot comment on treatment patterns as they pertain to palliative care or allied health services, we acknowledge the critical role these services play in end-of-life care for the population under study. Inferences drawn from our choropleth maps alone are potentially subject to bias by the modifiable areal unit problem, whereby apparent geographic trends are influenced by the locations of administrative boundaries [70]. Additionally, although our straight-line distance analysis was a simplification of how patients travel for cancer care, no single measure of distance can perfectly capture the multiple modes of transportation and routes of travel that individual patients use.

\section{Conclusion}

We identified regional variation in medical oncology consultation, receipt of chemotherapy, and overall survival for patients with non-curative esophagogastric cancer. These outcomes are negatively impacted by increasing distance from patient place of residence to the nearest cancer centre. Much opportunity exists to reduce barriers to care access and improve survival for non-curative esophagogastric cancer, both between individual patients and across geographic space. Future research and policy changes should take aim at improving entry into cancer care systems, improving the availability of high-volume providers, and ensuring that access to optimal assessment and treatment is improved without worsening the burden of distance.

Supplementary Information The online version contains supplementary material available at https://doi.org/10.1007/s10120-021-01157-w.

Acknowledgements This study was supported by ICES, which is funded by an annual grant from the Ontario Ministry of Health and Long-Term Care (MOHLTC). The opinions, results and conclusions reported in this paper are those of the authors and are independent from the funding sources. No endorsement by ICES or the Ontario MOHLTC is intended or should be inferred. Parts of this material are based on data and/or information compiled and provided by the Canadian Institute for Health Information (CIHI). However, the analyses, conclusions, opinions and statements expressed herein are those of the authors, and not necessarily those of CIHI. Parts of this material are based on data and information provided by Cancer Care Ontario (CCO). The opinions, results, view, and conclusions reported in this paper are those of the authors and do not necessarily reflect those of $\mathrm{CCO}$. No endorsement by CCO is intended or should be inferred.

Funding This work was supported by the Canadian Institutes of Health Research Partnerships for Health System Improvement (Grant number 154131).

\section{Compliance with ethical standards}

Conflict of interest Julie Hallet has received speaking honoraria from Ipsen Biopharmaceuticals Canada and Novartis Oncology. Natalie G. Coburn receives salary support from Cancer Care Ontario as the Clinical Lead for Patient Reported Outcomes.

Ethical standards All procedures followed were in accordance with the ethical standards of the responsible committee on human experimentation (institutional and national) and with the Helsinki Declaration of 1964 and later versions. For the conduct of this retrospective population-based study, informed consent was waived by the Research Ethics Board of Sunnybrook Health Sciences Centre.

\section{References}

1. Fitzmaurice C, Akinyemiju TF, Lami FHA, Alam T, AlizadehNavaei R, Allen C, et al. Global, regional, and national cancer incidence, mortality, years of life lost, years lived with disability, 
and disability-adjusted life-years for 29 cancer groups, 1990 to 2016: a systematic analysis for the global burden of disease study. JAMA Oncol. 2018;4:1553-68.

2. Zhang Y. Epidemiology of esophageal cancer. World J Gastroenterol. 2013;19:5598-606.

3. Ajani JA, Barthel JS, Bekaii-Saab T, Bentrem DJ, D’Amico TA, Das P, et al. Clinical practice guidelines in oncologyTM. J Natl Compr Canc Netw. 2010;8:32.

4. Hallet J, Davis LE, Mahar AL, Liu Y, Zuk V, Gupta V, et al. Variation in receipt of therapy and survival with provider volume for medical oncology in non-curative esophago-gastric cancer: a population-based analysis. Gastric Cancer. 2020;23:300-9.

5. Van Cutsem E, Moiseyenko VM, Tjulandin S, Majlis A, Constenla $\mathrm{M}$, Boni C, et al. Phase III study of docetaxel and cisplatin plus fluorouracil compared with cisplatin and fluorouracil as first-line therapy for advanced gastric cancer: a report of the V325 study group. J Clin Oncol. 2006;24:4991-7.

6. Bang Y-J, Van Cutsem E, Feyereislova A, Chung HC, Shen L, Sawaki A, et al. Trastuzumab in combination with chemotherapy versus chemotherapy alone for treatment of HER2-positive advanced gastric or gastro-oesophageal junction cancer (ToGA): a phase 3, open-label, randomised controlled trial. Lancet. 2010;376:687-97.

7. MacKenzie M, Spithoff K, Jonker D. Systemic therapy for advanced gastric cancer: a clinical practice guideline. Curr Oncol. 2011;18:e202-9.

8. Ajani JA, D’Amico TA, Almhanna K, Bentrem DJ, Besh S, Chao $\mathrm{J}$, et al. Esophageal and esophagogastric junction cancers, version 1.2015. J Natl Compr Canc Netw. 2015;13:194-227.

9. Smyth EC, Verheij M, Allum W, Cunningham D, Cervantes A, Arnold D. Gastric cancer: ESMO clinical practice guidelines for diagnosis, treatment and follow-up. Ann Oncol. 2016;27:v38-49.

10. Muro K, Van Cutsem E, Narita Y, Pentheroudakis G, Baba E, Li J, et al. Pan-Asian adapted ESMO clinical practice guidelines for the management of patients with metastatic gastric cancer: a JSMO-ESMO initiative endorsed by CSCO, KSMO, MOS. SSO and TOS Ann Oncol. 2019;30:19-33.

11. Sinding C, Warren R, Fitzpatrick-Lewis D, Sussman J. Research in cancer care disparities in countries with universal healthcare: mapping the field and its conceptual contours. Support Care Cancer. 2014;22:3101-20.

12. O'Connor SC, Mogal H, Russell G, Ethun C, Fields RC, Jin L, et al. The effects of travel burden on outcomes after resection of extrahepatic biliary malignancies: results from the US extrahepatic biliary consortium. J Gastrointest Surg. 2017;21:2016-24.

13. Lin CC, Bruinooge SS, Kirkwood MK, Olsen C, Jemal A, Bajorin $\mathrm{D}$, et al. Association between geographic access to cancer care, insurance, and receipt of chemotherapy: geographic distribution of oncologists and travel distance. J Clin Oncol. 2015;33:3177-85.

14. Latchana N, Davis L, Coburn NG, Mahar A, Liu Y, Hammad A, et al. Population-based study of the impact of surgical and adjuvant therapy at the same or a different institution on survival of patients with pancreatic adenocarcinoma: effect of location of surgical and adjuvant therapy on survival in pancreatic adenocarcinoma. BJS Open. 2019;3:85-94.

15. Kim Y-E, Gatrell AC, Francis BJ. The geography of survival after surgery for colo-rectal cancer in southern England. Soc Sci Med. 2000;50:1099-107.

16. Dejardin O, Bouvier AM, Faivre J, Boutreux S, De Pouvourville G, Launoy G. Access to care, socioeconomic deprivation and colon cancer survival. Aliment Pharmacol Ther. 2008;27:940-9.

17. Tracey E, McCaughan B, Badgery-Parker T, Young J, Armstrong BK. Patients with localized non-small cell lung cancer miss out on curative surgery with distance from specialist care: access to curative surgery in NSCLC patients. ANZ J Surg. 2015;85:658-63.
18. Dixon M, Mahar AL, Helyer LK, Vasilevska-Ristovska J, Law C, Coburn NG. Prognostic factors in metastatic gastric cancer: results of a population-based, retrospective cohort study in Ontario. Gastric Cancer. 2016;19:150-9.

19. Mahar AL, Coburn NG, Kagedan DJ, Viola R, Johnson AP. Regional variation in the management of metastatic gastric cancer in Ontario. Curr Oncol. 2016;23:250-7.

20. Davis LE, Coburn NG, Hallet J, Earle CC, Liu Y, Myrehaug S, et al. (2020) Material deprivation and access to cancer care in a universal health care system. Cancer. cncr.33107.

21. Yee EK, Coburn NG, Davis LE, Mahar AL, Zuk V, Gupta V, et al. Impact of geography on care delivery and survival for noncurable pancreatic adenocarcinoma: a population-based analysis. J Natl Compr Canc Netw. 2020;18:1642-50.

22. Canada health act. 2004 [cited 2019 Aug 21]. Available from: https://www.canada.ca/en/health-canada/services/health-caresystem/canada-health-care-system-medicare/canada-health-act. html

23. Benchimol EI, Smeeth L, Guttmann A, Harron K, Moher D, Petersen I, et al. The REporting of studies conducted using observational routinely-collected health data (RECORD) statement. PLOS Med. 2015;12:e1001885.

24. Alter DA, Naylor CD, Austin P, Tu JV. Effects of socioeconomic status on access to invasive cardiac procedures and on mortality after acute myocardial infarction. N Engl J Med. 1999;341:1359-67.

25. Elixhauser A, Steiner C, Harris DR, Coffey RM. Comorbidity measures for use with administrative data. Med Care. 1998;36:8-27.

26. Gutacker N, Bloor K, Cookson R. Comparing the performance of the Charlson/Deyo and Elixhauser comorbidity measures across five European countries and three conditions. Eur J Public Health. 2015;25:15-20.

27. Matheson FI, Dunn JR, Smith KL, Moineddin R, Glazier RH. Development of the Canadian marginalization index: a new tool for the study of inequality. Can J Public Health. 2012;103:S12-16.

28. Krieger N. Overcoming the absence of socioeconomic data in medical records: validation and application of a census-based methodology. Am J Public Health. 1992;82:703-10.

29. Iron K, Zagorski BM, Sykora K, Manuel DG. Living and dying in ontario: an opportunity for improved health information. Toronto: Institute for clinical evaluative sciences; 2008. p. 38.

30. Robles SC, Marrett LD, Aileen Clarke E, Risch HA. An application of capture-recapture methods to the estimation of completeness of cancer registration. J Clin Epidemiol. 1988;41:495-501.

31. Juurlink D, Preyra C, Croxford R, Chong A, Austin P, Tu J, et al. Canadian Institute for Health Information Discharge Abstract Database: a Validation Study. Toronto: Institute for Clinical Evaluative Sciences; 2006.

32. Government of Canada SC. Postal code OM conversion file. 2017 [cited 2019 Aug 21]. Available from: https://www150.statcan.gc. $\mathrm{ca} / \mathrm{n} 1 / \mathrm{en} / \mathrm{catalogue} / 92-154-\mathrm{X}$.

33. Government of Canada SC. Census divisions [Internet]. [cited 2019 Aug 21]. Available from: https://www12.statcan.gc.ca/ census-recensement/2016/dp-pd/hlt-fst/imm/GeoSelect-eng. $\mathrm{cfm}$ ?Lang $=\mathrm{E} \& \mathrm{~T}=23$.

34. Government of Canada SC. 2016 Census boundary files. 2016 [cited 2019 Aug 21]. Available from: https://www12.statcan.gc. ca/census-recensement/2011/geo/bound-limit/bound-limit-2016eng.cfm

35. 2014-2019 Systemic treatment provincial plan. Cancer care Ontario; 2014.

36. Meilleur A, Subramanian SV, Plascak JJ, Fisher JL, Paskett ED, Lamont EB. Rural residence and cancer outcomes in the united states: issues and challenges. Cancer Epidemiol Biomarkers Prev. 2013;22:1657-67. 
37. Paszat LF, Mackillop WJ, Groome PA, Zhang-Salomons J, Schulze K, Holowaty E (1998). Radiotherapy for breast cancer in Ontario: rate variation associated with region, age and income. Clin Invest Med 21.

38. Johnston GM, Boyd CJ, Joseph P, MacIntyre M. Variation in delivery of palliative radiotherapy to persons dying of cancer in nova scotia, 1994 to 1998. J Clin Oncol. 2001;19:3323-32.

39. Townsley C, Pond GR, Peloza B, Kok J, Naidoo K, Dale D, et al. Analysis of treatment practices for elderly cancer patients in Ontario. Canada J Clin Oncol. 2005;23:3802-10.

40. Groome PA, Schulze KM, Keller S, Mackillop WJ. Demographic Differences between Cancer Survivors and those who Die Quickly of their Disease. Clin Oncol. 2008;20:647-56.

41. Alvino DML, Chang DC, Adler JT, Noorbakhsh A, Jin G, Mullen JT. How far are patients willing to travel for gastrectomy? Ann Surg. 2017;265:1172-7.

42. Fong ZV, Loehrer AP, Fernández-del Castillo C, Bababekov YJ, Jin G, Ferrone CR, et al. Potential impact of a volume pledge on spatial access: a population-level analysis of patients undergoing pancreatectomy. Surgery. 2017;162:203-10.

43. Mavros MN, Coburn NG, Davis LE, Mahar AL, Liu Y, Beyfuss $\mathrm{K}$, et al. Low rates of specialized cancer consultation and cancerdirected therapy for noncurable pancreatic adenocarcinoma: a population-based analysis. Can Med Assoc J. 2019;191:E574-80.

44. Matheson FI, Moloney G, van Ingen T (2016) Ontario marginalization index user guide. Providence St. Joseph's and St. Michael's Healthcare

45. Maddison AR, Asada Y, Urquhart R. Inequity in access to cancer care: a review of the Canadian literature. Cancer Causes Control. 2011;22:359-66.

46. Groux $\mathrm{Ph}$, Anchisi S, Szucs Th. Are cancer patients willing to travel more or further away for a slightly more efficient therapy? Cancer Clin Oncol. 2014;3:36-42.

47. Resio BJ, Chiu AS, Hoag JR, Brown LB, White M, Omar A, et al. Motivators, barriers, and facilitators to traveling to the safest hospitals in the united states for complex cancer surgery. JAMA Netw Open. 2018;1:e184595.

48. Symer MM, Abelson JS, Yeo HL. Barriers to regionalized surgical care: public perspective survey and geospatial analysis. Ann Surg. 2019;269:73-8.

49. Brewer CA. Basic mapping principles for visualizing cancer data using geographic information systems (GIS). Am J Prev Med. 2006;30:S25-36.

50. Sears J, Khan K, Ardern CI, Tamim H. Potential for patient-physician language discordance in Ontario. BMC Health Serv Res. 2013; $13: 535$

51. Walter SD. The analysis of regional patterns in health data: II. The power to detect environmental effects. Am J Epidemiol. 1992;136:742-59.

52. Dumbrava MI, Burmeister EA, Wyld D, Goldstein D, O'Connell DL, Beesley VL, et al. Chemotherapy in patients with unresected pancreatic cancer in Australia: a population-based study of uptake and survival. Asia Pac J Clin Oncol. 2018;14:326-36.

53. Evans DB, Hsu J, Boerma T. Universal health coverage and universal access. Bull World Health Organ. 2013;91:546-546A.

54. Levit LA, Byatt L, Lyss AP, Paskett ED, Levit K, Kirkwood $\mathrm{K}$, et al. Closing the rural cancer care gap: three institutional approaches. JCO Oncol Pract. 2020;16:422-30.

55. Burge FI, Lawson BJ, Johnston GM, Grunfeld E. A populationbased study of age inequalities in access to palliative care among cancer patients. Med Care. 2008;46:1203-11.
56. Turner M, Fielding S, Ong Y, Dibben C, Feng Z, Brewster DH, et al. A cancer geography paradox? Poorer cancer outcomes with longer travelling times to healthcare facilities despite prompter diagnosis and treatment: a data-linkage study. Br J Cancer. 2017;117:439-49.

57. Massarweh NN, Chiang Y-J, Xing Y, Chang GJ, Haynes AB, You $\mathrm{YN}$, et al. Association between travel distance and metastatic disease at diagnosis among patients with colon cancer. J Clin Oncol. 2014;32:942-8.

58. Ahmed S, Shahid RK. Disparity in cancer care: a Canadian perspective. Curr Oncol. 2012 [cited 2019 Aug 21];19. Available from: http://www.current-oncology.com/index.php/oncology/artic le/view/1177.

59. Baldwin L-M, Cai Y, Larson EH, Dobie SA, Wright GE, Goodman DC, et al. Access to cancer services for rural colorectal cancer patients. J Rural Health. 2008;24:390-9.

60. O'Gorman LD, Hogenbirk JC, Warry W. clinical telemedicine utilization in Ontario over the Ontario telemedicine network. Telemed E-Health. 2016;22:473-9.

61. Brown EM. The Ontario telemedicine network: a case report. Telemed E-Health. 2013;19:373-6.

62. Birkmeyer JD, Goodney PP, Lucas FL (2003) Surgeon volume and operative mortality in the United States. N Engl J Med 11.

63. Bilimoria KY, Bentrem DJ, Feinglass JM, Stewart AK, Winchester DP, Talamonti MS, et al. Directing surgical quality improvement initiatives: comparison of perioperative mortality and long-term survival for cancer surgery. J Clin Oncol. 2008;26:4626-33.

64. Gooiker GA, van Gijn W, Wouters MWJM, Post PN, van de Velde CJH, Tollenaar RAEM, et al. Systematic review and meta-analysis of the volume-outcome relationship in pancreatic surgery. Br J Surg. 2011;98:485-94.

65. Hallet J, Davis L, Mahar A, Mavros M, Beyfuss K, Liu Y, et al. Benefits of high-volume medical oncology care for noncurable pancreatic adenocarcinoma: a population-based analysis. J Natl Compr Canc Netw. 2020;18:297-303.

66. Hallet J, Look Hong NJ, Zuk V, Davis LE, Gupta V, Earle CC, et al. (2019) Economic impacts of care by high-volume providers for non-curative esophagogastric cancer: a population-based analysis. Gastric Cancer. [cited 2020 Mar 27]; Available from: http:// link.springer.com/https://doi.org/10.1007/s10120-019-01031-w.

67. Birkmeyer JD. Regionalization of high-risk surgery and implications for patient travel times. JAMA. 2003;290:2703-8.

68. Stitzenberg KB, Sigurdson ER, Egleston BL, Starkey RB, Meropol NJ. Centralization of cancer surgery: implications for patient access to optimal care. J Clin Oncol. 2009;27:4671-8.

69. Diaz A, Pawlik TM. Optimal location for centralization of hospitals performing pancreas resection in California. JAMA Surg. 2020;155:261-3.

70. Openshaw S. The modifiable areal unit problem. Norwich: Geo books; 1983.

Publisher's Note Springer Nature remains neutral with regard to jurisdictional claims in published maps and institutional affiliations. 